2 Голубков Е. П. АВС и XYZ-анализ: проведение и оценка результативности // Маркетинг в России и за рубежом. 2010. №3. С. 12-23.

3 Галямов А. Ф., Тархов С. В. Управление взаимодействием с клиентами коммерческой организации на основе методов сегментации и кластеризации клиентской базы // Вестник Уфимского государственного авиационного технического университета. 2014 № 1 (99).

${ }^{4}$ Birant D. Data Mining Using RFM Analysis. Knowledge-Oriented Applications in Data Mining // InTech. 2011. C. 6-108.

\title{
APPLICATION OF SALES ANALYSIS TOOLS TO CUSTOMER SEGMENTATION IN TRADE
}

\author{
(C) 2020 Cheblukova Anna Alekseevna \\ Student \\ Samara State University of Economics \\ E-mail: annacheb@list.ru
}

Keywords: RFM analysis, segmentation, ABC-analysis, $\mathrm{XYZ}$-analysis, e-mail marketing, competitiveness, sales promotion, market segmentation, customer loyalty.

This article discusses the existing methods of sales analysis in order to segment customers, their purpose, application and their comparison. The author also gives a methodology for conducting RFM analysis of clients and describes the possible use of promotion methods for groups of clients obtained as a result of this analysis.

УДК 331.2

Код РИНЦ 06.77.00

АНАЛИЗ И ПЛАНИРОВАНИЕ РАСХОДОВ НА ОПЛАТУ ТРУДА

\author{
(c) 2020 Ченина Екатерина Сергеевна* \\ студент \\ Самарский государственный экономический университет \\ E-mail: cheninaes@mail.ru
}

Ключевые слова: анализ, планирование, прогнозирование, система управления персоналом, расходы на оплату труда.

В статье рассматривается вопрос оптимизации расходов на оплату труда, анализируются факторы, влияющие на эффективность системы планирования расходов на оплату труда, даны рекомендации по совершенствованию процесса управления трудовыми ресурсами и расходами на оплату их труда.

* Научный руководитель - Динукова Олеся Анатольевна, кандидат экономических наук, доцент. 
Стоимость рабочей силы в большинстве компаний, несомненно, является самой значительной переменной, которая может быть оптимизирована. Цели оптимизации расходов, как правило, следующие: минимизировать затраты на оплату труда персонала, не влияя на желаемый уровень обслуживания, с сохранением самого высокого уровня предоставления услуг ${ }^{1}$.

Для их достижения необходимо обратить внимание на следующие переменные:

1. Определение точного прогноза объема продаж и рыночной активности.

Прогнозирование уровня активности или продаж является первой задачей и отправной точкой в цепочке решений, которые повлияют на стоимость рабочей силы. При неправильном прогнозе продаж будет трудно оценить количество необходимой рабочей силы и легко ошибиться в планировании.

Прогноз должен иметь необходимый уровень детализации, чтобы иметь возможность обеспечить правильное определение размеров расходов, не забывая о том, что их определение должно быть перенесено в графики работ, по которым выполняется работа персоналом. Важно также учитывать трудовые нормы и договоры с работниками.

Существуют передовые аналитические методы для анализа расходов на оплату труда. Среди них есть те, которые могут точно предсказать продажи или активную деятельность. Например, методы трендового анализа, прогнозирования и перекрестной проверки показателей отчетности. Использование данных методов предполагает накопленный массив данных. Наличие инструментов, основанных на этих методах, имеет решающее значение для достижения высокого уровня точности планирования данного вида затрат ${ }^{2}$.

2. Диагностика уровня профессиональной подготовки работников и навыков, необходимых каждой должности для достижения ожидаемого уровня ключевых показателей.

Для того, чтобы достичь высокого уровня обслуживания клиентов, следует определить конкретные требования каждой работы и нанимать персонал с соответствующим уровнем знаний и опыта. Важно продумать и определить, какая подготовка нужна для нанимаемых должностей, так как это необходимо учитывать в дальнейшем при формировании конфигурации и планировании коллектива.

3. Подбор персонала для каждой службы исходя из прогноза ожидаемой активности и профессиональных возможностей для обеспечения высокого уровня обслуживания 3.

Система управления персоналом должна быть построена таким образом, чтобы в любом момент возможно было определить размер команды в соответствии с ожидаемой активностью и желаемым уровнем обслуживания клиентов. Нужно принимать во внимание навыки и способности, которыми должна обладать команда, чтобы гарантировать это обслуживание. Также нельзя забывать, что действующие правила и соглашения могут стать ограничителями при создании идеальной команды. Определение размеров должно быть детализировано во времени, чтобы обеспечить его выполнение и соответствие требованиям. Оптимизация расходов на оплату труда должна быть направлена на то, чтобы сбалансировать потребности компании с регулированием и соблюдением трудового договора и/или коллективных соглашений. 
Существуют методы в области анализа расходов на оплату труда и экономикоматематические модели, которые помогают работодателям определить соответствующие расходы на оплату труда, а также количественно-квалификационные требования.

4. Минимизация затрат на рабочую силу при условии их равномерного распределения с течением времени.

Система анализа и планирования расходов на оплату труда, помимо минимизации затрат на рабочую силу и гарантирования определенного уровня обслуживания, должна соответствовать огромному количеству ограничений и правил.

Помимо учета расходов на оплату труда каждого работника и конкретных требований его квалификационных характеристик, планирование расходов должно соответствовать всем правилам, содержащимся в соглашениях и положениях. Например, в отношении оплаты отпусков, больничных и командировок, которые немного усложняют проблему планирования оплаты труда. Кроме того, проблема становится более острой, если задействовано большое количество единиц оборудования или на предприятии существует высокая частота планирования.

В настоящее время существуют передовые аналитические методы в области анализа и планирования расходов на оплату труда, которые могут в значительной степени помочь работодателям решить эту проблему. Эти методы позволяют учесть все переменные анализа и планирования таких затрат и автоматизировать генерацию данных с использованием современных программных комплексов для автоматизации данных задач, гарантирующих соблюдение всех установленных законодательно и на локальном уровне ограничений, предлагая наиболее подходящее решение для поставленных задач, например, минимизацию трудозатрат.

5. Мониторинг и сопоставление плановых и фрактических расходов на оплату труда.

Измерение является основой для изучения и оценки результатов планирования, а также того, как оно приближается или отдаляется от реальных потребностей бизнеса и его повседневной деятельности.

Определение набора показателей, которые позволят проанализировать и управлять процессом оптимизации расходами на оплату труда - является неотъемлемой частью данного процесса. Важна максимальная точность и системность данных показателей. Это позволит повлиять на процесс принятия управленческих решений, а также оценить эффрективность планирования 4 .

6. Построение и внедрение системы ежедневной оценки результатов на основе программных комплексов и систем автоматизации процессов с использованием передовых экономико-математических моделей для определения ключевых областей управления с целью совершенствования процесса анализа и планирования расходов на оплату труда для поддержания процесса непрерывного совершенствования. Использование инструментов бюджетирования в области управления персоналом позволяет более гибко регулировать финансовые потоки организации, точнее планировать и контролировать их расходование на запланированные результаты деятельности 5 .

Анализ - это финальный шаг к пониманию и определению областей улучшения и определению того, какие решения в сфрере управления расходами на оплату труда были 300 
ошибочными. Это также позволяет определить почему запланированный результат не был достигнут.

Анализ должен основываться на всей информации, полученной в ходе планирования, а также на мерах и показателях производительности, рассчитанных на предыдущем этапе. Поэтому важно, чтобы вся соответствующая информация создавалась и хранилась на протяжении всего процесса планирования в поддержку этого анализа.

В результате такого анализа должны быть определены и осуществлены действия и меры на некоторых этапах процесса планирования с целью улучшения показателей, которые приближают управление расходами на оплату труда к запланированному.

Измерение и анализ должны быть непрерывными и носить частый характер, поскольку они являются основой для постоянного совершенствования процесса управления трудовыми ресурсами и расходами на оплату их труда.

1 Митрофанова И. А. Управление экономикой труда на предприятии: учеб. пособие. Волгоград: ВолгГТУ, 2018. С.12.

2 Динукова О.А. Оценка влияния трудовых факторов на объем производства и реализации продукции // Проблемы развития предприятий: теория и практика: материалы 18-й Междунар. науч.-практ. конфф., 19-20 декабря 2020 г. - Самара: Изд-во Самар. гос. экон. ун-та, 2019. С. 13-16.

3 Рынок труда: учеб./под общ. ред. Ж. Батчулууна и Б. Бэхтора. - Улаанбаатар : Содпресс, 2019. - C.94.

${ }^{4}$ Егоршин А. П. Мотивация трудовой деятельности: учеб. пособие. М.: Инфрра-М, 2017. C.285.

5 Динукова О.А. Бюджетирование трудовых затрат //Х Междунар.науч.-практ. конф. "Региональные проблемы преобразования экономики: интеграционные процессы и социальноэкономическая политика региона", г. Махачкала, 05 декабря 2018 г. С. 546-548. https://elibrary.ru/item.asp?id=37128032

\title{
ANALYSIS AND PLANNING OF EXPENSES ON PAYMENT OF LABOR
}

\author{
(C) 2020 Chenina Ekaterina Sergeevna \\ Student \\ Samara State University of Economics \\ E-mail: cheninaes@mail.ru
}

Keywords: analysis, planning, forecasting, personnel management system, labor costs.

Abstract: the article deals with the issue of optimization of labor costs; analyzes the factors that affect the effectiveness of the system of planning labor costs; provides recommendations for improving the process of managing labor resources and expenses for their labor. 